\title{
Assessing the Effect of nearly-Zero Energy Buildings on Distribution Systems by Means of Quasi-Static Time Series Power Flow Simulations
}

\author{
Pablo Arboleya, Miguel Huerta, Bassam Mohamed, Cristina González-Morán \\ Dept. of Electrical Engineering \\ University of Oviedo \\ Gijón, Spain
}

\author{
Xavier Domínguez \\ Dept. de Automatización y Control \\ Escuela Politécnica Nacional \\ Quito, Equador
}

\begin{abstract}
In the present work, an integrated software able to assess the impact of the nearly-Zero Energy Buildings (nZEBs) over the distribution network is presented. The software creates quasi-static time series for the buildings consumption, generation and storage systems and combines this data with power flow analyses of the grid. The European regulation already imposed the massive use of nZEB in the short-term. To implement these systems, the use of a central coordination scheme at the distribution level is expected. However, nZEBs are being currently installed in a "selfish" manner, trying to minimise the energy exchanged with the grid based on an individual building basis. Therefore, it is necessary the development of a methodology and a tool to evaluate the impact of nZEB in this uncoordinated scenario that will take place in Europe in the coming years.
\end{abstract}

Index Terms - Quasi-static time series, distribution systems simulation, nZEB, Power Flow, Backward/Forward Swept, Current injection, Impact assessment, nZEB, CI.

\section{INTRODUCTION}

To date, the impact of distributed generators (DGs) in distribution systems has been widely studied. The coordinated use of DGs, Energy Storage (ES) devices and Loads has been revealed as the most popular solution to reduce the impact of DG devices in the network. For instance, in [1], the Distribution System Operators (DSO) coordinate the mentioned resources for voltage control purposes. In [2], the coordination of the ES systems, allows the DSO to provide other ancillary services like frequency control.

Special attention has been paid to the use of ES systems as a powerful tool for mitigating the harmful effects of the massive penetration of photovoltaic generators $(\mathrm{PV})$ on the distribution feeders [3]. The European Union Directive 2010/31/UE [4] states that by 2018 , all buildings owned or occupied by public authorities must be nZEB, and eventually, all residential buildings should be adapted to fulfil the same requirements. Therefore, nZEBs should be equipped with DG and ES resources. NZEBs will represent a natural way to accommodate DG and ES into the distribution network. However, in the short term, as nZEBs will not be coordinated, the reduction

\footnotetext{
Corresponding author email: arboleyapablo@uniovi.es

This work was partially supported by the Spanish Ministry of Science and Innovation under Grant ENE2013-44245-R (MICROHOLO Development of a Holistic and Systematical Approach to AC Microgrids Design and Management)
}

of their impact on the network [5] derived from a coordinated action or the chance to provide ancillary services [6] will not be possible. In the present work, a software for assessing the impact of nZEBs in the distribution system is described and evaluated. This software is an extension of the GenMIX package [7]. In this particular study, no central coordination or collaborative strategy among the buildings was considered.

This work uses quasi-static time series for feeding the power flow solver due to the great variability in the distribution network generation derived from the use of PV panels. This approach is widely accepted among researchers [8]-[10]. In sections II and III, the employed power flow algorithm and the main models and features implemented in the GenMIX software for simulating the nZEB's will be respectively described. In section IV, the proposed scenario for carrying out the impact assessment will be presented. Section V will analyse the obtained results and finally, a set of conclusions will be stated in section VI.

\section{POWER FLOW ALGORITHM}

The power flow algorithm implemented for solving the problem is based in the current injection method (CI), and it is formulated in a matrix compact way. The pseudocode of the

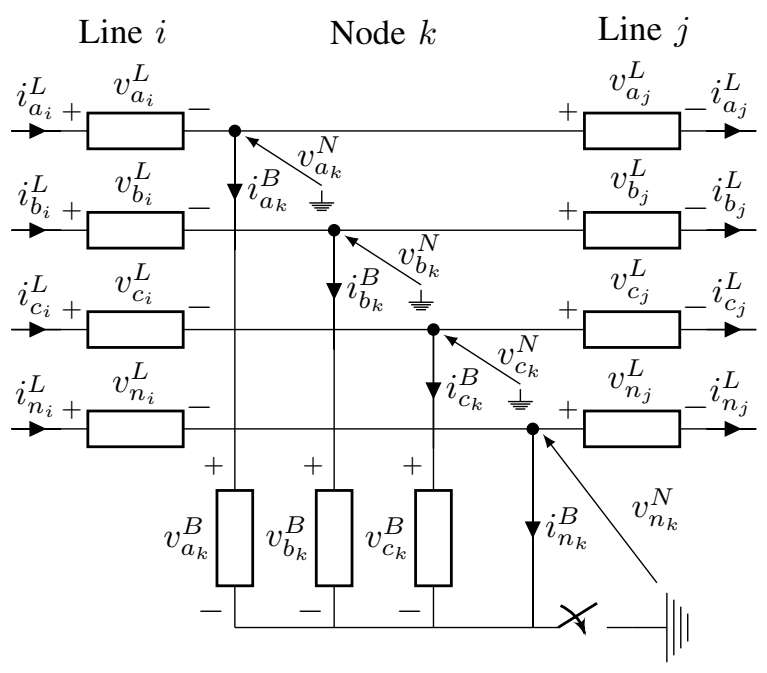

Fig. 1: Representation and nomenclature for nodes and lines. 


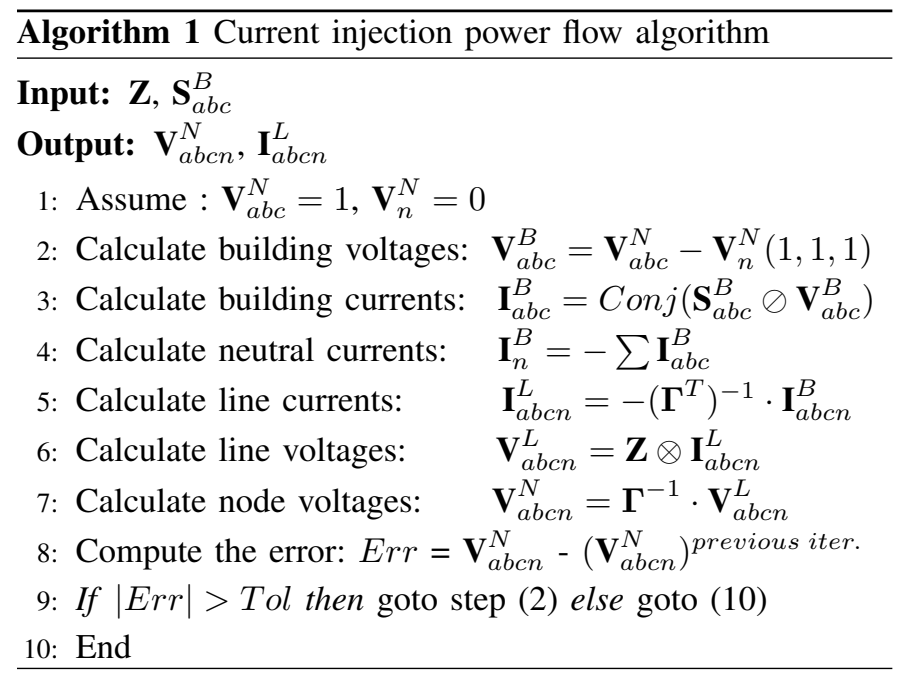

$\otimes$ : element-wise multiplication $\oslash$ : element-wise division

proposed algorithm as well as the formulation is represented in Algorithm 1.

The inputs of the algorithm are the impedances of the lines $(\mathbf{Z})$ and the powers demanded or injected by the buildings or the aggregation of the buildings $\left(\mathbf{S}_{a b c}^{B}\right) . \mathbf{Z}$ is a $(n \times 4)$ matrix representing the impedances of all lines ( $n$ represent the number of lines). $\mathbf{S}_{a b c}^{B}$ is a ( $\left.n \times 3\right)$ matrix with all powers consumed/injected by the buildings or aggregation of buildings in all nodes. All the nodes except the slack node are PQ nodes representing a single nZEB or an aggregation of nZEBs. In the next section the methodology for obtaining such powers will be explained.

It is assumed that slack node does not contain buildings. The apparent powers of this node are not considered at this stage. Without considering the slack, and because the feeders are radial, the number of nodes of the system will be equal to the number of lines. The active power will be considered positive when it is demanded from the grid. The row $k$ of the matrix $\mathbf{S}_{a b c}^{B}$ will represent the power of building or aggregation of buildings placed at $k^{\text {th }}$ node.

The outputs of the algorithm will be the voltages in all nodes respect to the ground $\left(\mathbf{V}_{a b c n}^{N}\right)$ and the current in all lines $\left(\mathbf{I}_{a b c n}^{L}\right) . \mathbf{V}_{a b c n}^{N}$ is a $(n \times 4)$ matrix. The row $k$ contains the four node voltages $\left(v_{a_{k}}^{N}, v_{b_{k}}^{N}, v_{c_{k}}^{N}, v_{n_{k}}^{N}\right)$ (See Fig. 1). It can be decomposed in a three column vector containing voltages of the phases respect to ground $\left(\mathbf{V}_{a b c}^{N}\right)$ and a column vector with the neutral to ground voltage $\left(\mathbf{V}_{n}^{N}\right)$. In case the neutrals are grounded at building level (TN schemes), $\mathbf{V}_{n}^{N}$ will be set to zero, otherwise neutral voltage will be set as one of the unknowns. $\mathbf{I}_{a b c n}^{L}$ is a $(n \times 4)$ matrix containing the current through all lines (phases and neutral). The row $i$ will represents the $i^{t h}$ line and it will contain $\left(i_{a_{i}}^{L}, i_{b_{i}}^{L}, i_{c_{i}}^{L}, i_{n_{i}}^{L}\right)$ (See Fig. 1).

The phase to ground voltages are initialised to 1 p.u. in all nodes and the neutral to ground voltages are initialised to zero. In step 2), the phase to neutral voltages in the buildings $\left(\mathbf{V}_{a b c}^{B}\right)$ are computed. $\mathbf{V}_{a b c}^{B}$ is a $(n \times 3)$ matrix. The row $k$ represent the building or aggregation of buildings at node $k$ and it is the vector $\left(v_{a_{k}}^{B}, v_{b_{k}}^{B}, v_{c_{k}}^{B}\right)$ (See Fig. 1).

In the step 3), using the voltage profile of the current iteration, the phase and neutral currents of the buildings $\left(\mathbf{I}_{a b c}^{B}\right)$ are calculated. It must be considered that $\mathbf{I}_{a b c n}^{B}$ is a $(n \times 4)$ matrix that can be decomposed in $\left(\mathbf{I}_{a b c}^{B}\right)(n \times 3)$ containing the phase currents and $\left(\mathbf{I}_{n}^{B}\right)(n \times 1)$ containing neutral currents. The row $k$ will represent the building or aggregation of buildings placed at node $k$ and it will contain $\left(i_{a_{k}}^{B}, i_{b_{k}}^{B}, i_{c_{k}}^{B}, i_{n_{k}}^{B}\right)$ (See Fig. 1). Once the buildings phase currents are obtained the neutral currents are computed (step 4)).

With the use of the node incidence matrix $(\boldsymbol{\Gamma})$, all line currents are calculated from the building currents (step 5)). Each row of $\boldsymbol{\Gamma}$ represents a line and each column represent a node. The element $\Gamma_{i k}$ will be 1 if the node $k$ is the tail of the line $i$ and it will be -1 in case the node $k$ is the head of line $i . \Gamma_{i k}$ will be zero otherwise. In the proposed algorithm, the last column of the matrix representing the slack node has been removed so the matrix is squared and regular. The voltage drop through the lines $\left(\mathbf{V}_{a b c n}^{L}\right)$ is obtained in step 7). $\mathbf{V}_{a b c n}^{L}$ is a $(n \times 4)$ matrix. Each row represents a line, for the $i^{\text {th }}$ line the structure is the $\operatorname{next}\left(v_{a_{i}}^{L}, v_{b_{i}}^{L}, v_{c_{i}}^{L}, v_{n_{i}}^{L}\right)$.

The line voltages are used to compute the new values of the nodal voltages (step 8)) that will be compared with the ones from the previous iteration (step 9)). If the error is below the tolerance the algorithm will be stopped, if not, it will return to the step number 2 .

\section{NZEB SIMULATION}

The active and reactive powers demanded or injected in the nodes are calculated by means of the software GenMIX, developed by the authors and described in this section. This software was initially conceived for making adequacy assessment studies in residential nZEBs. For a specific building configuration and a mix of DG and ES devices, a set of reliability indices (like for instance, the estimation of the energy imported from the grid in a regular year, the number of hours that the building is going to be importing or exporting energy to the grid) can be computed. The program also creates an economic study with outputs like the payback of the investment, among others. Another important feature of the program is its ability to generate hourly quasi-static time series with the power demanded by all dwellings, generators and storage systems in the building. It is this last feature the one exploited in this study.

Each building will be simulated as a set of dwellings connected to the different phases. Each dwelling can be defined depending on the number of inhabitants and their profile. The total load of the building for a specific hour will be calculated from a bottom-up approach considering all the appliances and loads inside each dwelling. The program can consider different kinds of generators like $\mu$ wind turbines, PV panels, diesel, fuel cells... However, in this study only PV panels were considered as they are expected to be the most common type of DG employed in urban environments. All the technical characteristics of the panels as well as the latitude, longitude and a database with temperatures and a climate Markov model can be configured.

The ES of the building tries to minimise at every moment the energy exchange with the grid. For this purpose, the building management system will try to charge the storage device when an energy surplus exist inside the building, and it will try 


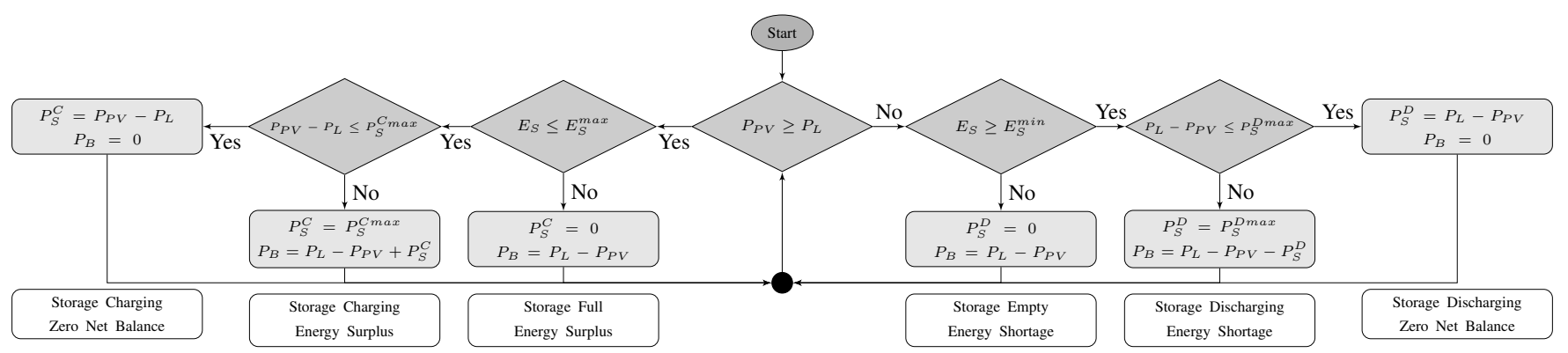

Fig. 2: Energy storage system management flowchart.
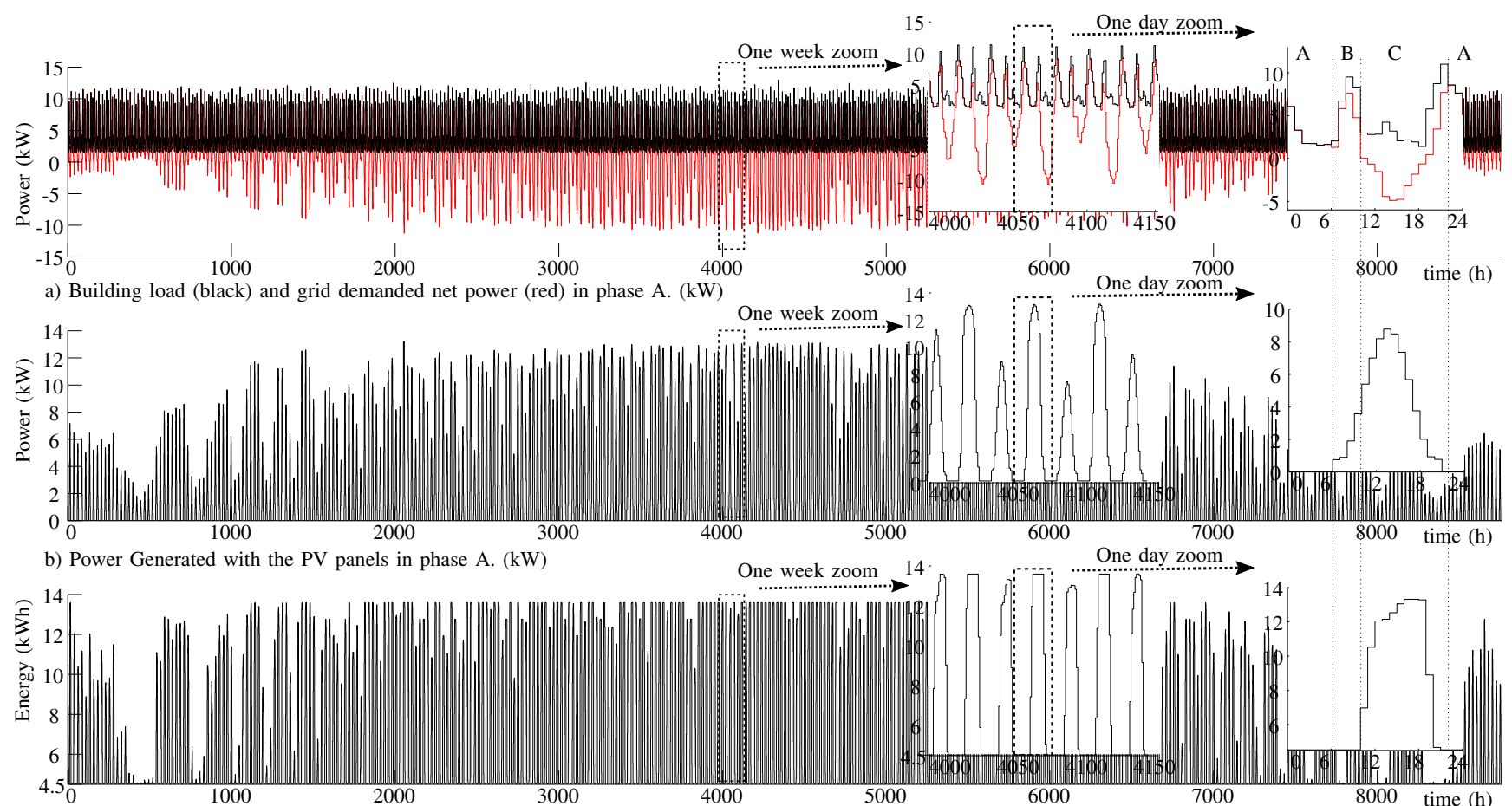

c) Energy stored in the batteries in $\mathrm{kWh}$

Fig. 3: Analysis of the demand, generation and net behaviour of Building in Node 32.

to discharge it when the demand exceeds the generation. A simple flowchart representing the ES device working mode is represented in Fig. 2. $P_{L}, P_{P V}$ represent respectively the power consumed by loads of the building and the power generated by the PV panels. $P_{S}^{C}$ and $P_{S}^{D}$ represent the charging and discharging power of the storage device and $E_{S}$ the energy stored in it. Finally $P_{B}$ is the net power that the building demands from the grid. A negative net power represents power injected into the grid. A more detailed description of the software can be found in [7].

In Fig. 3, one of the 340 different buildings considered for the case of study is presented. In Fig. 3 a) the total power demanded by all building loads is represented in black, and the net power exchanged between the building and the grid in red. In Fig. 3 b) the power generated by the building PV panels is depicted.

Finally, Fig. 3 c) represents the energy stored in the building accumulation system. In the one day zoomed representation it can be observed how in this specific case the unoccupied period from 9:00 a.m. to 18:00 p.m. is the one that prevails in this specific building.

\section{DESCRIPTION OF THE PROPOSED SCENARIO}

A modification of the IEEE 123 node test feeder was selected for this study. Each node of the microgrid was loaded with 4 buildings. The unbalanced behaviour of the buildings was also taken into account. For selecting the size of the buildings, the model of the city of Gijon (in the north of Spain) was considered. The size of the buildings varies between 9 and 54 dwellings. The dwellings can be small $\left(60 \mathrm{~m}^{2}\right)$, medium $\left(80 \mathrm{~m}^{2}\right)$ or large $\left(120 \mathrm{~m}^{2}\right)$ size. The number of occupants in each dwelling can vary according to the size of the dwelling from 1 to 7 inhabitants. The storeys of the buildings vary from three to nine.

Each building can be equipped with PV generation and ES devices based on lithium batteries. The number of buildings equipped with PV generation and ES devices vary depending on the case of study. For estimating the installed PV power in a given building, it was considered that $3 / 4$ of the rooftop was covered with panels. The rooftop surface can be estimated depending on the surface of the dwellings, the number and size of dwellings and the number of floors of the specific building. The rooftop was assumed to be horizontal. The 
TABLE I: Hours with maximum building consumption, generation and minimum energy exchanged between buildings and grid.

\begin{tabular}{|c|c|c|c|c|c|c|c|c|c|c|c|c|c|c|c|c|c|}
\hline Stage & \begin{tabular}{|l|} 
PV \\
pen \\
$(\%)$
\end{tabular} & ES & $\begin{array}{l}\text { Max. } \\
\text { Comp. } \\
\text { Day }\end{array}$ & $\begin{array}{l}\text { Max. } \\
\text { Gen. } \\
\text { Day }\end{array}$ & $\begin{array}{l}\text { Min. } \\
\text { Imp. } \\
\text { Day }\end{array}$ & $\begin{array}{l}\text { Max. } \\
\text { Comp. } \\
\text { Hour }\end{array}$ & $\begin{array}{l}\text { Max. } \\
\text { Gen. } \\
\text { Hour }\end{array}$ & $\begin{array}{l}\text { Min. } \\
\text { Imp. } \\
\text { Hour }\end{array}$ & $\begin{array}{c}\text { Slack } \\
\text { Energy } \\
\text { Max. Comp. } \\
(M W h)\end{array}$ & $\begin{array}{c}\text { Slack } \\
\text { Energy } \\
\text { Max. Gen. } \\
(M W h)\end{array}$ & $\begin{array}{c}\text { Slack } \\
\text { Energy } \\
\text { Min. Imp. } \\
(k W h)\end{array}$ & $\begin{array}{c}\text { Buildings } \\
\text { Energy } \\
\text { Max. Comp. } \\
(M W h)\end{array}$ & $\begin{array}{l}\text { Buildings } \\
\text { Energy } \\
\text { Max. Gen. } \\
(M W h)\end{array}$ & $\begin{array}{l}\text { Buildings } \\
\text { Energy } \\
\text { Min. Imp. } \\
(k W h)\end{array}$ & $\begin{array}{c}\text { Energy } \\
\text { Losses } \\
\text { Max. Comp. } \\
(k W h)\end{array}$ & \begin{tabular}{|c|} 
Energy \\
Losses \\
Max. Gen. \\
$(k W h)$
\end{tabular} & $\begin{array}{c}\text { Energy } \\
\text { Losses } \\
\text { Min. Imp. } \\
(k W h)\end{array}$ \\
\hline 1 & 0 & No & 279 & 198 & 198 & 21 & - & 3 & 4.84 & - & 681.66 & 4.60 & - & 677.51 & 237.13 & - & 4.15 \\
\hline 2 & 15 & No & 335 & 159 & 246 & 21 & 11 & 10 & 4.85 & -0.46 & 1.40 & 4.61 & -0.46 & 0.73 & 236.53 & 3.85 & 0.67 \\
\hline 3 & 15 & Yes & 335 & 178 & 189 & 21 & 12 & 11 & 4.89 & -0.35 & 0.81 & 4.65 & -0.35 & -0.09 & 241.32 & 2.86 & 0.90 \\
\hline 4 & 25 & No & 335 & 131 & 142 & 21 & 11 & 15 & 4.87 & -1.18 & -1.35 & 4.63 & -1.19 & -2.45 & 238.98 & 15.01 & 1.09 \\
\hline 5 & 25 & Yes & 335 & 192 & 190 & 21 & 14 & 15 & 4.89 & -1.11 & 0.85 & 4.65 & -1.12 & 0.05 & 240.25 & 13.04 & 0.79 \\
\hline 6 & 35 & No & 139 & 176 & 6 & 21 & 12 & 13 & 4.88 & -1.83 & 0.33 & 4.64 & -1.86 & -0.06 & 242.30 & 31.31 & 0.39 \\
\hline 7 & 35 & Yes & 279 & 149 & 97 & 21 & 14 & 14 & 4.88 & -1.81 & 0.09 & 4.63 & -1.84 & -0.17 & 242.93 & 31.02 & 0.26 \\
\hline 8 & 50 & No & 139 & 179 & 332 & 21 & 12 & 13 & 4.89 & -2.67 & 1.40 & 4.65 & -2.73 & 1.09 & 244.15 & 62.21 & 0.31 \\
\hline 9 & 50 & Yes & 335 & 149 & 269 & 21 & 14 & 10 & 4.84 & -2.66 & $\begin{array}{l}-0.70 \\
\end{array}$ & 4.60 & -2.72 & $\begin{array}{l}-0.86 \\
\end{array}$ & 237.07 & 61.89 & 0.16 \\
\hline 10 & 75 & No & 139 & 187 & 332 & 21 & 12 & 11 & 4.94 & -3.91 & -0.60 & 4.69 & -4.04 & -0.66 & 248.40 & 129.75 & 0.06 \\
\hline 11 & 75 & Yes & 279 & 183 & 341 & 21 & 14 & 12 & 4.81 & -3.92 & 0.15 & 4.58 & -4.05 & 0.10 & 236.98 & 129.64 & 0.06 \\
\hline 12 & 100 & No & 139 & 179 & 1 & 21 & 12 & 15 & 4.89 & -4.71 & 0.60 & 4.64 & -4.90 & 0.44 & 241.67 & 186.90 & 0.17 \\
\hline 13 & 100 & Yes & 328 & 183 & 2 & 21 & 14 & 11 & 4.73 & -4.73 & 0.34 & 4.56 & -4.89 & 0.33 & 169.75 & 155.05 & 0.02 \\
\hline
\end{tabular}

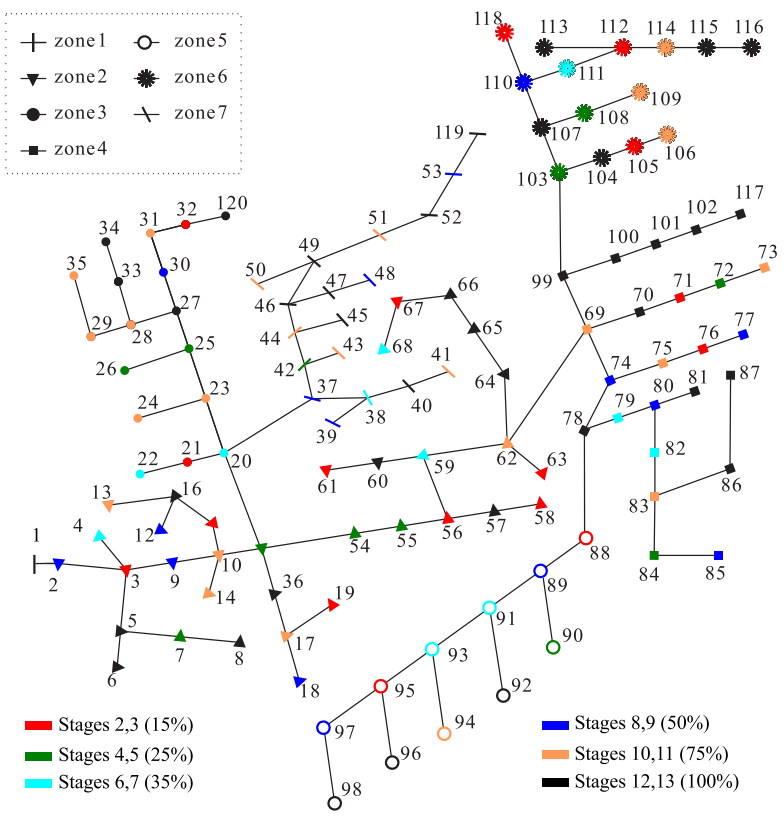

Fig. 4: IEEE 123 Nodes test system. The different colours represent the nodes where the nZEB were activated.

selected PV panel was the Talesun TP660 PB with a rated power of $(270 \mathrm{~W} /$ panel $)$ in standard conditions. The panels were installed with a fixed tilt, in a way that partial shadowing between them was avoided. An economical restriction was also considered. The cost of the PV panels in a building should be no more than $1000 €$ times the number of dwellings of the building.

ES systems are only installed in buildings with PV generation. The storage capacity covers $1 / 3$ of the standard daily energy consumption of the building. This particular size was selected so the ES systems were not oversized nor extremely costly. The maximum charge/discharge power in $k W$ is $(1 / 3)$ of energy capacity in $k W h$.

In the base case, only conventional buildings were considered. In successive stages, a percentage of buildings were equipped with PV and PV plus ES devices. In Fig. 4, the nodes with PV or PV plus ES are depicted. In Tables I and II the level of PV penetration and the usage of ES devices depending on the stage/case can be observed. The level of penetration varies from zero (base case) to $100 \%$ (cases 12 and 13).
TABLE II: Analysis of the aggregated yearly values of the energy imported and exported at slack level and the energy imported, exported and self consumed at building level.

\begin{tabular}{|c|c|c|c|c|c|c|c|c|c|}
\hline Stage & $\begin{array}{c}\text { PV } \\
\text { pen } \\
(\%)\end{array}$ & ES & $\begin{array}{c}E^{i m p} \\
\text { slack } \\
(G W h)\end{array}$ & $\begin{array}{c}E^{\text {exp }} \\
\text { slack } \\
(G W h)\end{array}$ & $\begin{array}{c}E^{\text {imp }} \\
\text { build } \\
(G W h)\end{array}$ & $\begin{array}{c}E^{\text {self }} \\
\text { build } \\
(G W h)\end{array}$ & $\begin{array}{c}E^{\text {exp }} \\
\text { build } \\
(G W h)\end{array}$ & $\begin{array}{c}\text { Loss } \\
(M W h)\end{array}$ & $\begin{array}{c}\text { Loss } \\
\text { Red. } \\
(\%)\end{array}$ \\
\hline 1 & 0 & No & 17.96 & 0.00 & 17.50 & 0.00 & 0.00 & 463.24 & 0.00 \\
\hline 2 & 15 & No & 15.38 & 0.13 & 16.27 & 1.23 & 1.42 & 397.44 & 14.20 \\
\hline 3 & 15 & Yes & 15.28 & 0.06 & 15.91 & 1.58 & 1.07 & 381.18 & 17.71 \\
\hline 4 & 25 & No & 14.57 & 0.67 & 15.69 & 1.81 & 2.18 & 385.03 & 16.88 \\
\hline 5 & 25 & Yes & 14.28 & 0.42 & 15.15 & 2.34 & 1.65 & 359.56 & 22.38 \\
\hline 6 & 35 & No & 14.01 & 1.36 & 15.14 & 2.36 & 2.88 & 384.31 & 17.04 \\
\hline 7 & 35 & Yes & 13.53 & 0.93 & 14.42 & 3.07 & 2.17 & 348.89 & 24.69 \\
\hline 8 & 50 & No & 13.53 & 2.40 & 14.37 & 3.12 & 3.64 & 395.60 & 14.60 \\
\hline 9 & 50 & Yes & 12.76 & 1.74 & 13.41 & 4.09 & 2.74 & 346.47 & 25.21 \\
\hline 10 & 75 & No & 12.95 & 4.14 & 13.34 & 4.16 & 4.97 & 437.36 & 5.59 \\
\hline 11 & 75 & Yes & 11.85 & 3.20 & 12.07 & 5.43 & 3.79 & 366.82 & 20.82 \\
\hline 12 & 100 & No & 12.65 & 5.35 & 12.69 & 4.81 & 5.88 & 483.28 & -4.33 \\
\hline 13 & 100 & Yes & 11.32 & 4.25 & 11.26 & 6.24 & 4.50 & 307.68 & 33.58 \\
\hline
\end{tabular}

\section{ANALYSIS OF THE RESUlTS}

Once the system was loaded with the quasi-static series obtained from the buildings, a set of results summarised in this section were obtained. With this kind of simulation, several types of analysis can be carried out. One of them could be a detailed analysis of the anual consumption, generation and energy stored in a given building like the one depicted in Fig. 3 . An analysis of the voltage variation during the whole year in the three phases at the point of common coupling of the building with the grid can be also obtained. Other possible option consists on aggregated analyses like the ones presented in the boxplot (Fig. 5) or the Tables I and II.

In Fig. 5, the phase A voltages obtained in cases 1, 8, 9 and 13 for the zone 2 nodes are depicted. The network is dimensioned for conventional buildings, so for the base case (in blue) most of the voltages in zone 2 (between quartile 25 and 75) are between 0.93 p.u. and 0.99 p.u. For this case, no outliers were obtained. The analysis of the voltages for the case $9(50 \%$ of PV penetration plus ES, in red) reveals a significant improvement in the voltage profile with a mean voltage no lower than 0.98 and most of the cases varying from 0.94 to 1 . In this case no outliers were observed. Case 8 (in yellow) is similar to case 9 (in red), but in the former, there are no storage devices in buildings. The mean voltage in both cases is similar in all nodes, but in this case without storage, a significant amount of outliers appeared with voltages lower than 0.92 p.u. or higher than 1.06 p.u. Finally, in the case 13 


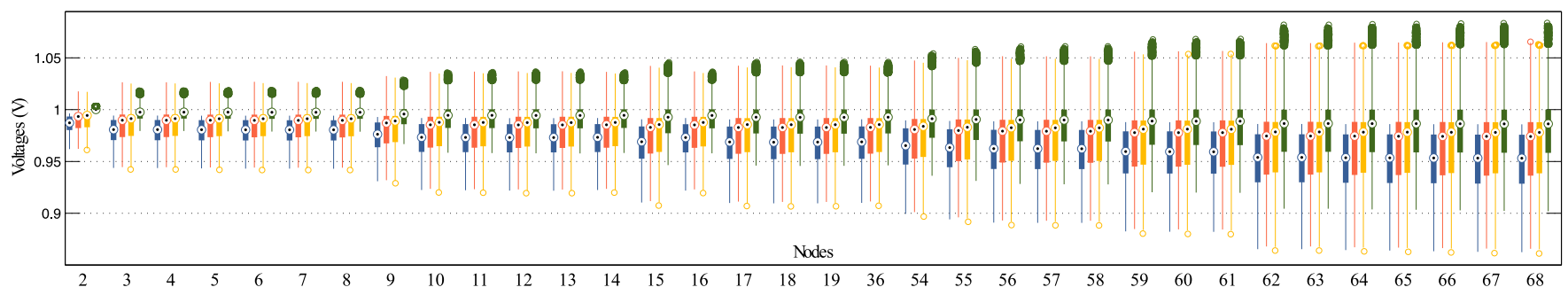

Fig. 5: Zone 2 nodal voltage in case 1 (No DG) in blue, case 9 (50\% of DG but no storage) in red, case 8 (50\% of DG plus storage) in yellow and case 13 (100\% of DG plus storage) in green.

(in green), the mean voltage profile is near 1p.u. in all nodes, but an approximate amount of $20 \%$ of the instants are consider as outliers with voltage levels above 1.06.

In Table I, the hours of the year with higher net building consumption, higher net building generation and lower amount of energy exchanged between the buildings and the grid are exposed. It must be noticed that even when the day with the maximum net building demand varies depending on the case of study, the hour with higher net building demand is always 21:00. It is interesting too the fact that the energy demanded from the slack during the maximum consumption hour is very similar in all the cases (between $4.84 \mathrm{MWh}$ and $4.94 \mathrm{MWh}$ ). It always corresponds to cases in which there is a high consumption, there is no PV generation (obviously), and most of the storage devices are empty. An increase in the storage capacity would prevent this behaviour.

The hour with maximum net generation varies from 10:00 to 15:00 depending on the case. In all cases except the base one, there is an energy surplus in the grid at that specific hour, so the energy at the slack level is negative. The higher the penetration level of nZEBs, the higher the energy surplus. For cases with the same level of DG penetration, the energy surplus is higher when the buildings are not equipped with storage system. The energy surplus varies from $0.46 \mathrm{MWh}$ (case 2) to $4.73 \mathrm{MWh}$ (case 13). It must be remarked that in this last case the energy surplus in the whole grid is in the same order than the energy consumed in the hour of maximum consumption.

The hour in which the energy exchange between the buildings and the network is minimum (Minimum impact hour), is also shown in Table I. In all the cases except the base case, the amount of energy imported or exported at slack level is lower than $2 \mathrm{kWh}$.

Table II contains the aggregated data for the whole year, total energy imported and exported at slack level, total energy imported and exported at building level, the energy fraction generated in the buildings that is self-consumed and the grid losses. As it can be observed, the best solution in terms of energy savings is the one obtained in the case 13 (100\% of DG with storage) with a reduction in losses of $33.58 \%$, and a total amount of energy imported at slack level of $11.32 \mathrm{GWh}(37 \%$ lower than the amount of energy imported in the base case). However, the case 9 (50\% of DG with ES) present similar figures with half cost and much better voltage profile as it was previously commented.

\section{CONCLUSIONS}

In this paper, a comprehensive methodology for assessing the impact of nZEBs in distributions networks was presented. For this purpose, the GenMix software, previously developed to perform reliability assessment in nZEBs, was complemented with a power flow module able to simulate the different states of the system depending on the quasi-static time series representing the buildings active and reactive power demands and injection. The mentioned software provides results in the form of temporal series (voltages, currents, actives and reactive powers) as well as aggregated data. As an example, the IEEE 123 node test feeder was simulated with different levels of nZEB penetration and the results obtained with the proposed software were shown and analysed. Further developments will include, different central coordination procedures, improve the software graphical user interface and include an automatic scenario generator and analysis module based on big data techniques.

\section{REFERENCES}

[1] Y. Wang, K. T. Tan, X. Y. Peng, and P. L. So, "Coordinated control of distributed energy-storage systems for voltage regulation in distribution networks," IEEE Transactions on Power Delivery, vol. 31, no. 3, pp. 1132-1141, June 2016.

[2] S. Chen, T. Zhang, H. B. Gooi, R. D. Masiello, and W. Katzenstein, "Penetration rate and effectiveness studies of aggregated bess for frequency regulation," IEEE Transactions on Smart Grid, vol. 7, no. 1, pp. 167-177, Jan 2016.

[3] M. J. E. Alam, K. M. Muttaqi, and D. Sutanto, "Mitigation of rooftop solar pv impacts and evening peak support by managing available capacity of distributed energy storage systems," IEEE Transactions on Power Systems, vol. 28, no. 4, pp. 3874-3884, Nov 2013.

[4] "Directive 2010/31/EU of the european parliament and of the council of 19 may 2010 on the energy performance of buildings," European Comission, 2010.

[5] F. Marra, G. Yang, C. Træholt, J. Østergaard, and E. Larsen, "A decentralized storage strategy for residential feeders with photovoltaics," IEEE Transactions on Smart Grid, vol. 5, no. 2, pp. 974-981, March 2014.

[6] Q. Li, R. Ayyanar, and V. Vittal, "Convex optimization for des planning and operation in radial distribution systems with high penetration of photovoltaic resources," IEEE Transactions on Sustainable Energy, vol. 7, no. 3, pp. 985-995, July 2016.

[7] P. Arboleya, E. X. Domíguez, and F. M. Lorenzo, "Unified generating and storing capacity reliability evaluation in nearly-zero energy buildings," in 2015 IEEE Power Energy Society General Meeting, July 2015, pp. 1-5.

[8] P. Chen, S. Tao, X. Xiao, and L. Li, "Uncertainty level of voltage in distribution network: an analysis model with elastic net and application in storage configuration," IEEE Transactions on Smart Grid, vol. PP, no. 99 , pp. 1-1, 2016.

[9] J. Wu and X. Guan, "Coordinated multi-microgrids optimal control algorithm for smart distribution management system," IEEE Transactions on Smart Grid, vol. 4, no. 4, pp. 2174-2181, Dec 2013.

[10] I. Miranda, H. Leite, and N. Silva, "Coordination of multifunctional distributed energy storage systems in distribution networks," IET Generation, Transmission Distribution, vol. 10, no. 3, pp. 726-735, 2016. 